\title{
Effects of Geometrical Properties of Rectangular Trenches Intended for Passive Isolation in Sandy Soils
}

\author{
Mehrab Jesmani ${ }^{1}$, Arash Moghadam Fallahi ${ }^{1}$ \& Hamed Faghihi Kashani ${ }^{1}$ \\ ${ }^{1}$ Department of Civil Engineering, Imam Khomeini International University, Qazvin, Iran \\ Correspondence: Hamed Faghihi Kashani, Department of Civil Engineering, Imam Khomeini International \\ University, Qazvin, Iran. Tel: 98-912-370-4837. E-mail: Hamed.faghihey@gmail.com
}

Received: May 2, 2012 Accepted: May 16, 2012 Online Published: June 19, 2012

doi:10.5539/esr.v1n2p137

URL: http://dx.doi.org/10.5539/esr.v1n2p137

\begin{abstract}
Wave barriers are placed actively and passively in the ground to reduce the transmission of vibration produced by industry, traffic, train, etc. They include open trenches, in-filled trenches and sheet piles, etc. In most recent studies, the researchers have worked on parameters such as depth, width, length of trenches and also, the distance between the source of vibration and trench in cohesive soils. Most researches are evaluation on screening induced by shallow foundation. In this study the passive isolation has been investigated with the help of open trenches screening against the vibration produced by deep foundations in sandy soils, and the effect of trench angle and radius have been studied. Moreover, the reasons for amplitude increasing before open trenches have been evaluated. Three dimensional finite element analyses (FEM) with ANSYS software are used to achieve an exact parametric study on passive screening. The assumed strains are less than $10^{-3}$ so the bilinear Elasto-Plastic behavior has been utilized.
\end{abstract}

Keywords: passive isolation, Rayleigh wave, pile foundation, ANSYS program, open trench, trench radius and trench angle

\section{Introduction}

It is obvious that vibration occurred by machines, structures, and dynamic systems is destructive; Firstly, because of their inculcating stresses and vibrations which can cause failure or fatigue on nearby structures and, Secondly because of the aggravating effect of vibration on the performance of vibration producer. So isolating structures against vibration created by traffic jam, machine foundations, explosion and earthquake has become an undeniable subject in engineering science.

Wave barrier is one of the solutions for this problem. Installing wave barriers near the sensitive structures is called passive isolation. Regarding to the literature of vibrations (Barkan, 1962) conducted an open trench screen to isolate a building against vibrations created by vehicle traffic and reported that screening is not a workable system for mitigating vibrations. In addition, he mentioned that open trench dimensions are related to the wavelength of the surface motion.

Woods (1967-1970) investigated the screening performance of trench's different parameters by conducting a series of field tests in active and passive isolation. Woods used rectangular open trenches for his research and also defined amplitude Reduction ratio (Arr). Furthermore, his research concluded that the thickness of the passive open trenches has an unimportant effect on their workability. In addition, Woods reported that effective trenches have a depth between $\frac{1}{2}$ to $\frac{1}{5}$ times of the Rayleigh wavelength.

Wass (1972) presented that amplitude is reduced by screening when the frequency is high. Aboudi (1973) worked on the ground surface response of wave barriers affected by time-dependent loading in an elastic half-space with the help of finite difference method (FDM). Woods et al. (1974) evaluated the screening efficiency of hollow cylindrical piles as a passive system in a half-space model.

Haupt (1977) and G. Segol et al. (1978) investigated the effect of shape and trench dimension on amplitude reduction by the help of finite element method (FEM). Liao and Sangrey (1978) examined the effect of piles as a wave barrier against Raleigh waves with high wavelength. They announced that in the case of impractical trenches, piles are the best choice for reducing the wave amplitude. In addition, Fuykui and Matsumoto (1980) 
considered the open trench efficiency on reduction of Rayleigh, P, SV and SH waves amplitude by using a two-dimensional method through finite difference method (FDM).

May and Bolt (1982) contemplated on the utilization of open trenches against compression and shear waves under the assumption of plane strain condition. Beskos et al. (1985-1991) worked on a complete series of numerical models which contains in-filled and open trenches isolation in continuously homogeneous and non-homogenous soils under the assumption of plane strain condition and by using boundary element method (BEM). They reported that if the depth of soil layer be less than 2.5 times that of Raleigh wavelength, the depth of trench must be at least2 times that of layer thickness.

Ahmad and Al-Hussaini (1991-2000) examined the effectiveness of active and passive isolation of circular open trenches. Besides, they investigated the effect of depth, width and location of the trenches by the usage of BEM method. Yeh et al. (1997) assessed the efficiency of open and in-filled trenches on reducing the vibration induced by train movement. This research showed that using trench barriers against vibration with low frequency is useless.

Kattis et al. (1999) examined the isolation of open trenches, in-filled trenches and pile barriers against the vibration produced by machinery foundations. Moreover, Shirvasta et al. (2002) explored the efficiency of open and in-filled trenches for screening Rayleigh waves by using 3D FE model.

Shen-Haw and Hung-Ta (2004) worked on the open and in-filled trenches as barriers for vibrations occurred by train movement. The results show that the adjacent building foundations have an important effect on vibration reduction.

Adam and Estroff (2005) deliberated the efficiency of open and in-filled trenches in reducing the six-storey building vibrations due to passing trains by using a two-dimensional FEM analysis. The results show that these barriers could reduce 80 percent of the vibrations. Also, they reported that open trenches are more effective in vibration reduction than in-filled trenches. El Nagger and Chehab (2005) conducted a numerical research using two-dimensional model to evaluate the screening effectiveness of open and in-filled trenches on reducing the pulse-induced waves of shallow foundations resting on an elastic half-space.

Celebi et al. (2006) with the help of finite element method (FEM) showed that using an open trench has an important effect on reduction of vibration amplitudes induced by passing trains. In addition, they presented two mathematical models and numerical techniques for solving problems related to wave propagation. Gaoet al. (2006) inspected the effect of pile barriers designed in rows as a passive screening by a three-dimensional model. The results show that piles with small diameter act like open trenches in reducing vibrations. Furthermore, they show that the distances between piles in a row are more important than the distances between rows of piles. Karlstorm and Bostrom (2007) investigated the opus of open trenches on reduction of wave amplitude induced by trains. They located these trenches in the both side of a railway and reported that these trenches could noticeably reduce the vibration amplitude especially at frequencies in the range of 2-8 Hertz.

Tsai et al. (2007) worked on active isolation provided by pile barriers against vibration induced by shallow foundations under vertical loading. They investigated the effect of pile dimensions, pile distances, pile materials and screening location. They reported that steel pipe is generally better than other solid piles, and a concrete hollow pile barrier can be ineffective because of its stiffness.

Jesmani et al. (2008) studied the effect of geometrical properties of an open trench intended for active isolation of deep foundations resting on a homogenous half-space cohesive soil by using a three-dimensional finite element method (FEM). In addition, Jesmani et al. (2011) conducted a research to evaluate the effect of geometrical properties of an open trench intended for passive isolation of deep foundation in sandy soils. Moreover, in this research the effect of soil properties and loading time has been investigated by using two-dimensional model in finite element method (FEM).

From the above review, most researches have focused on in-filled and open trenches as an active barrier against vibrations induced by shallow foundations. In addition, the effect of geometrical properties of trenches has been investigated such as depth, width, location, etc.

In this study, the ground passive isolation of deep foundations have been studied by open trenches in sandy soils and also the effect of two important parameters; trench radius and trench angle, have been evaluated.

\section{Propagation and Attenuation Characteristics of Deep Foundation}

The form of wave propagation is different in shallow foundations and deep foundations. Attewell and Farmer (1973) worked on wave propagation of deep pile foundations. Their results are depicted in Figure 1. The waves 
which are induced by deep pile foundations in the ground are elastic waves in the form of shear waves, surface waves and compression waves. Each of these waves propagates differently; Shear and compression waves propagate radially in all directions from the pile toe on a spherical wave front, but Raleigh waves and surface waves propagate radially on a cylindrical wave front along the surface. Because of the geometrical damping, both body waves and Rayleigh waves decrease in amplitude by increasing the distance.

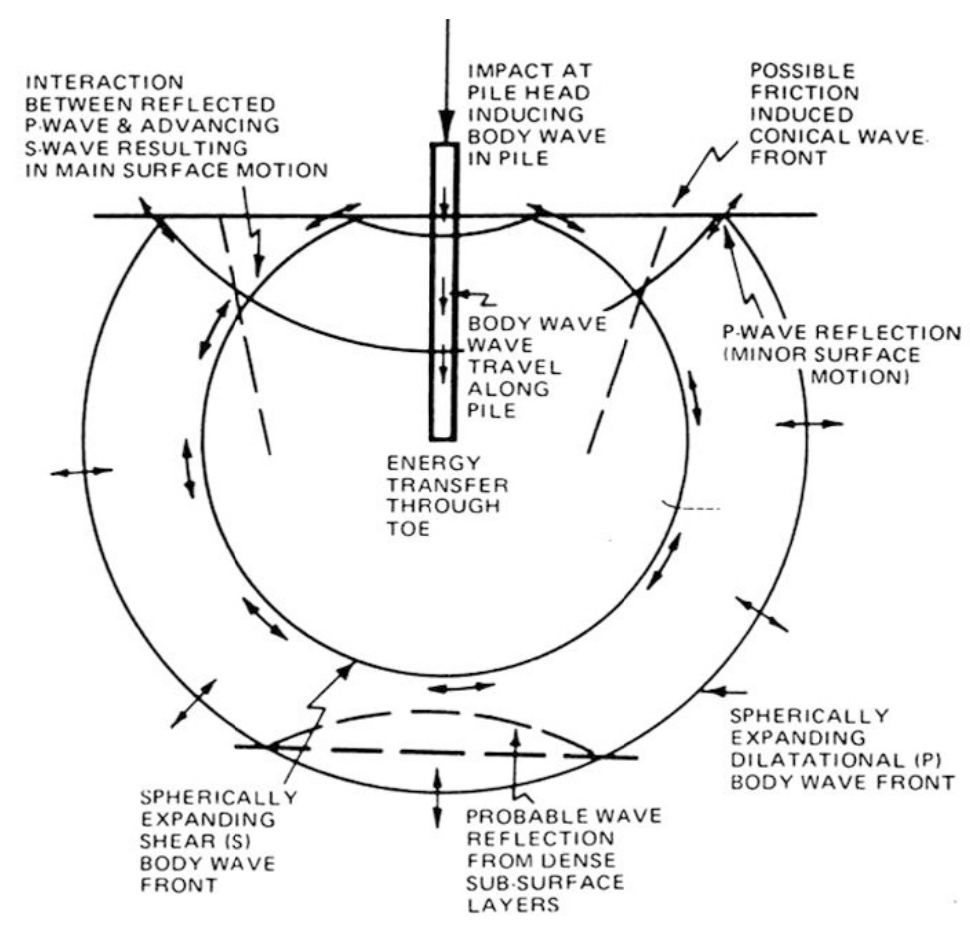

Figure 1. Wave propagation induced by deep foundation (Attewell \& Farmer, 1973)

Wolf (1994) reported that the attenuation of ground vibrations in the far field is inversely related to the square of the area of the wave front; $\mathrm{r}^{-\mathrm{n}}$ with $\mathrm{r}$ the distance and $\mathrm{n}$ the geometrical attenuation coefficient. The second parameter is equal to $0.5,1$ and 2 for surface waves propagating on a cylindrical wave front, body waves propagating on a spherical wave front and body wave propagating along the surface respectively.

\section{Problem Definition, Assumptions, and Loading Condition}

A rigid concrete (Table 1) foundation of height $1.5 \mathrm{~m}$ and of radius $3.5 \mathrm{~m}(\mathrm{Rf})$, with 9 piles of diameter $70 \mathrm{~cm}$, length D defined for this problem. Besides, this foundation is rested on a sandy soil layer (Tables 2 and 3 ) with a limited thickness of length Ls and thickness Hs, underlain by a hard stratum. This foundation is subjected to a harmonic $(\mathrm{f}=2 \mathrm{HZ})$ compressive and concentrated load P0 $\sin (\omega \mathrm{t})$ with $\mathrm{P} 0=29430 \mathrm{~Pa}$ (or $0.3 \mathrm{~kg} / \mathrm{cm}^{2}$ ).

Table 1. Concrete properties

\begin{tabular}{ccccc}
\hline & Young's Modulus & Poisson's Ratio & Density & Material Damping \\
\hline \multirow{3}{*}{ Concrete } & $\mathrm{E}_{\mathrm{s}}$ & $\mathrm{v}$ & $\rho$ & $\beta_{\mathrm{s}}$ \\
& $\left(\frac{\mathrm{N}}{\mathrm{m}^{2}}\right)$ & - & $\left(\frac{\mathrm{kg}}{\mathrm{m}^{3}}\right)$ & - \\
$(1)$ & $2 \mathrm{E}+10$ & 0.2 & 2500 & $2 \%$ \\
\hline
\end{tabular}

An annular open trench of depth $\mathrm{H}$ and width $\mathrm{w}$ is located at the distance $\mathrm{L}$ which is the shortest distance from a point on the circumference of circular foundation and the annular trench. Moreover, the isolated building is located at the center of the annular trench with the radius of $\mathrm{R}$ and $\theta$ (the degree measure of the trench arc) (Figures 2, 3 and Table 4). 
The foundation is assumed to be restrained against horizontal movement and the soil is under assumption of being isotropic and homogenous with linear soil behavior for low deformation.

Table 2. Static properties of the sandy soil

\begin{tabular}{cccccccc}
\hline $\begin{array}{c}\text { Static } \\
\text { Properties }\end{array}$ & $\begin{array}{c}\text { Young's } \\
\text { Modulus }\end{array}$ & $\begin{array}{c}\text { Poisson's } \\
\text { Ratio }\end{array}$ & $\begin{array}{c}\text { Specific } \\
\text { Weight }\end{array}$ & Density & $\begin{array}{c}\text { Material } \\
\text { Damping }\end{array}$ & \multicolumn{2}{c}{$\begin{array}{c}\text { Soil Mechanical } \\
\text { Parameters }\end{array}$} \\
\hline \multirow{2}{*}{ Soil } & $E_{S}$ & $v$ & $\gamma_{s}$ & $\rho$ & $\beta_{s}$ & $C$ & $\varphi$ \\
& $\left(\frac{k N}{m^{2}}\right)$ & - & $\left(\frac{k N}{m^{3}}\right)$ & $\left(\frac{k g}{m^{3}}\right)$ & - & $\left(\frac{k N}{m^{2}}\right)$ & Degree \\
$(1)$ & 50000 & 0.35 & 19 & 1936.80 & $5 \%$ & 10 & 40 \\
\hline
\end{tabular}

Table 3. Dynamic properties of the sandy soil

\begin{tabular}{ccccc}
\hline Dynamic & $G_{s}$ & $V_{s}$ & $K$ & $V_{r}$ \\
Properties & Shear modulus & Shear wave velocity & $V_{r}=K . V_{s}$ & Rayleigh wave velocity \\
\hline Soil & $\left(\frac{k N}{m^{2}}\right)$ & $\frac{m}{s}$ & - & $\frac{m}{s}$ \\
& 33333 & 131 & 0.936 & 123 \\
\hline$(1)$ & &
\end{tabular}

Table 4. Geometric properties of the trench and deep foundation

\begin{tabular}{ccc}
\hline Explanation & Value & Unit \\
\hline Trench Depth $(\mathrm{H})$ & 20 & $\mathrm{~m}$ \\
Pile Length(D) & 10 & $\mathrm{~m}$ \\
Trench Angle $(\theta)$ & $90,120,150,180$ & $\circ$ \\
Trench Width(w) & 1 & $\mathrm{~m}$ \\
Trench Radius $(\mathrm{R})$ & $15,20,25$ & $\mathrm{~m}$ \\
Trench Location $(\mathrm{L})$ & $\mathrm{R}, 2 \mathrm{R}, 3 \mathrm{R}$ & ---- \\
\hline
\end{tabular}

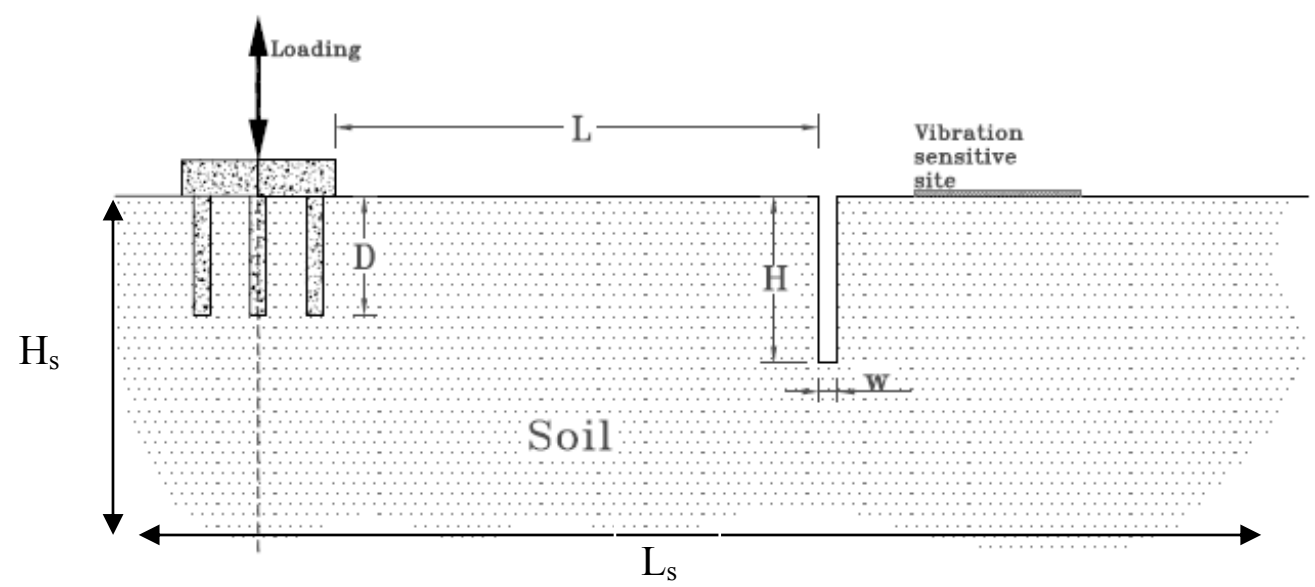

Figure 2. Problem definition - Section of passive isolation by open trench 


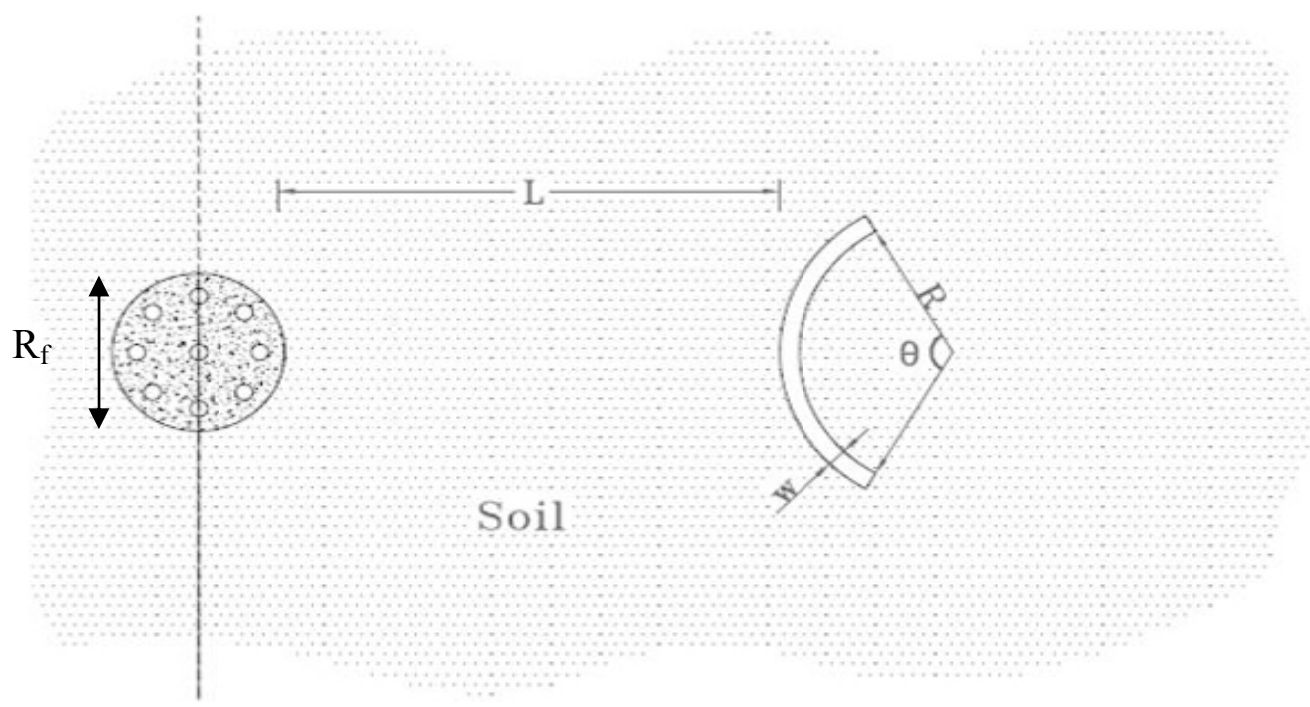

Figure 3. Problem definition - Plan of passive isolation by open trench

\section{Geometric Model}

For reduction in computation time, and with the help of axisymmetrey in plan, only $\frac{1}{4}$ of the actual model has been built in the model (Figure 4). In order to eliminate the effect of wave reflection, the depth of model has been taken more than 30 meter (Jesmani, 2008).

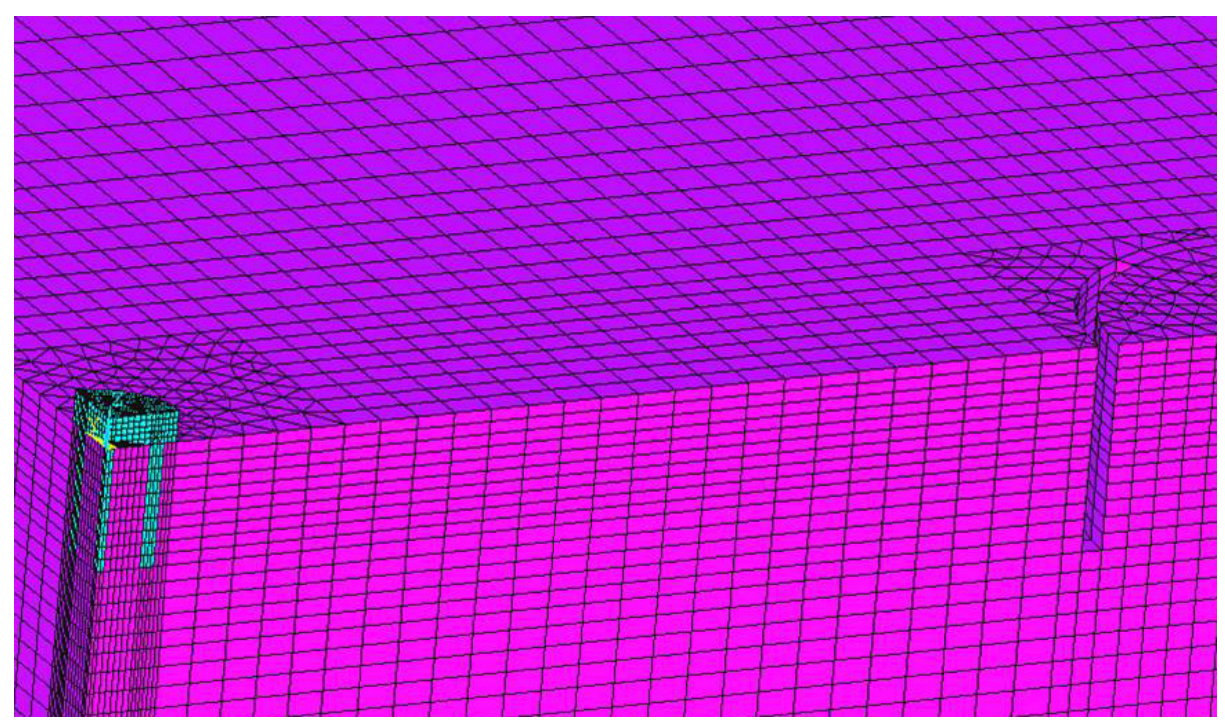

Figure 4 . Model geometry of passive isolation by open trench

\section{Finite Element Model}

The most effective properties in evaluating wave propagation in low strains are damping, Poisson's ratio, stiffness and density. Because the predicted strains have been less than $10^{-3}$, abilinear Elasto-Plastic model is applied to evaluate the soil behavior. In addition in this condition shear modulus is also an essential parameter (Figure 5) (Ishihara, 1996).

To investigate the behavior of the model such as sliding or any possible separation at the soil structure interface, three-dimensional surface-to-surface contact elements (TARGE 170, CONTA 174) have been employed. In the places with high concentration of stress or places needed to be focused for strains computation, such as foundation, three-dimensional elements Solid 95 (Figure 6) have been used. This element defined by twenty nodes having three degrees of freedom in the directions of $\mathrm{x}, \mathrm{y}$ and $\mathrm{z}$ at each node. 
Normal contact stiffness factor was assumed to be equal to 1 and 0.6 was taken to maximum contact friction coefficient. Solid 45 (Figure 7) is employed to model the soil in places that weren't play an important role in the results. This element is defined by eight nodes which have three degrees of freedom in each node.

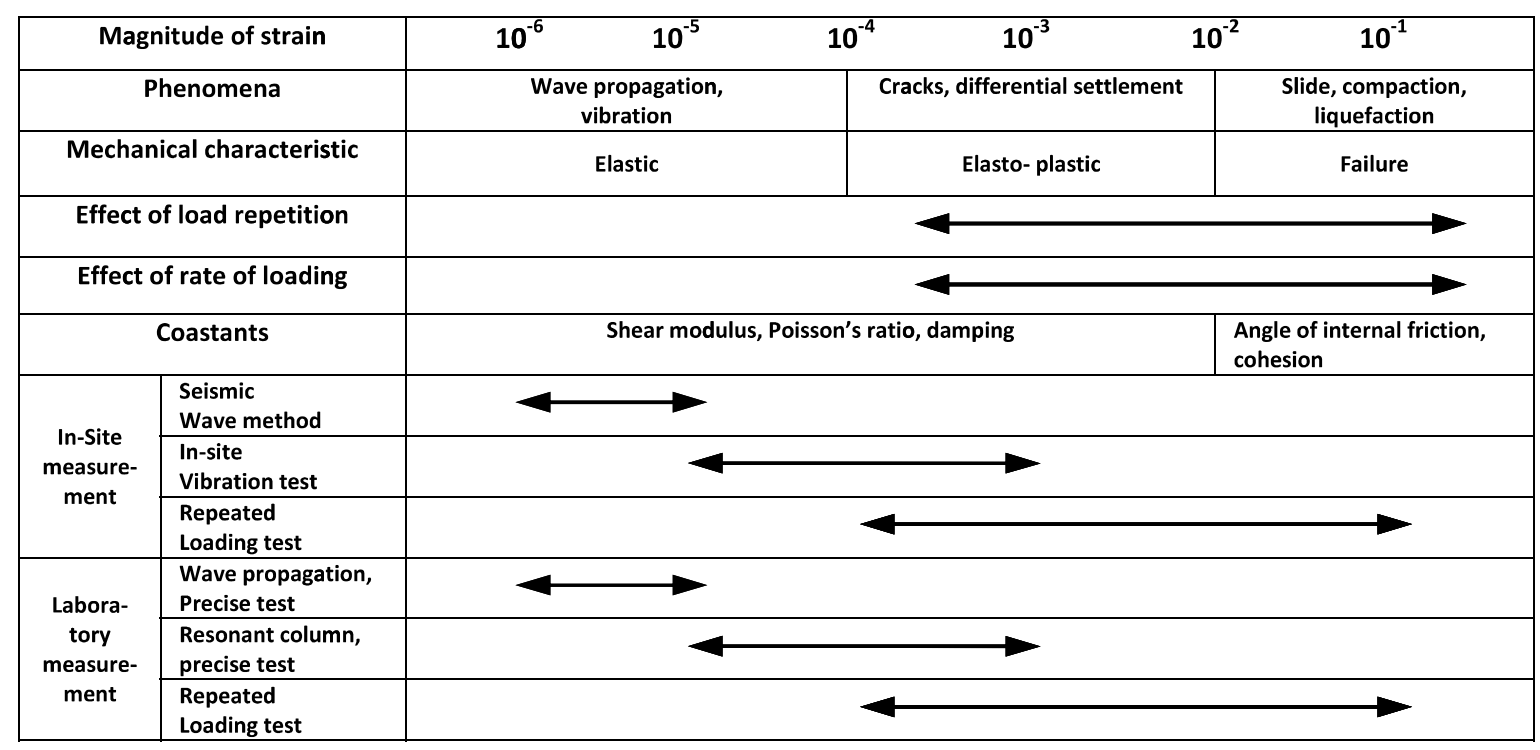

Figure 5. Soil behavior models in accordance with magnitude of strain (Ishihara, 1996)
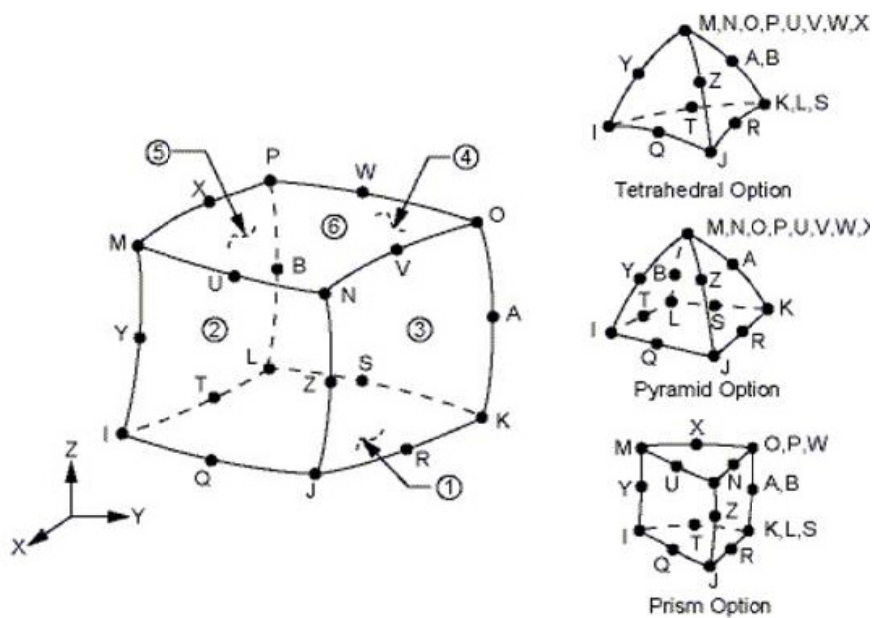

Figure 6. Twenty-node element (SOLID95) 


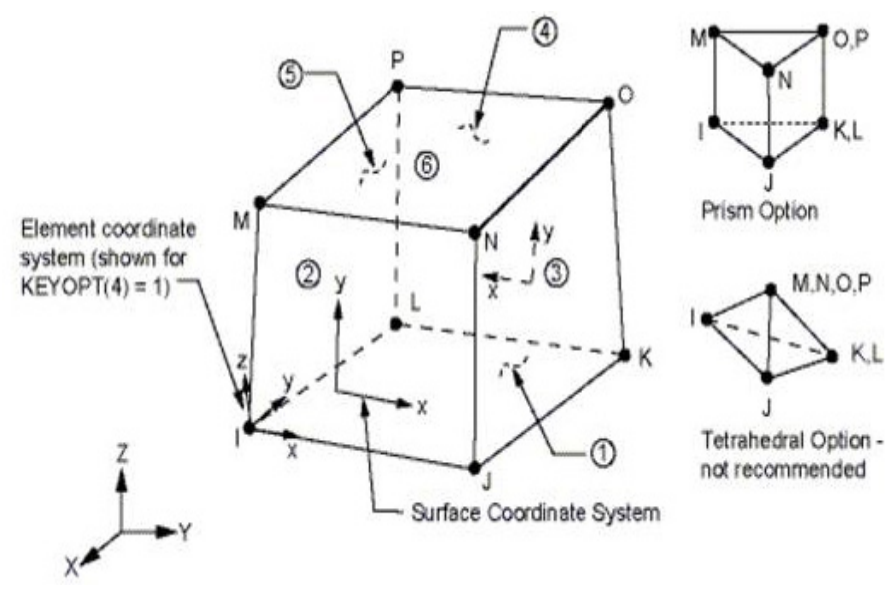

Figure 7. Eight-node Element (SOLID45)

\section{Meshing and Boundary Condition}

The mesh dimension has been taken 0.25 times of the shortest Rayleigh wavelength with loading frequency of $50 \mathrm{HZ}$ near the foundation. In addition, 1.5 meter length of element has been taken for the longest Rayleigh wavelength induced by low loading frequency of $2 \mathrm{HZ}$.

The above range for the mesh dimension is between $\frac{1}{8}$ to $\frac{1}{35}$ of Rayleigh wavelength, and in accordance with the suggestions of researchers this range is acceptable. By increasing the distance from the trench outer edge, the element size increases. The boundary nodes are restrained in $\mathrm{X}$ and $\mathrm{Y}$ directions. In accordance with the necessity of hard stratum underlaid the soil layer, it assumed to be restrained in three directions. The meshing model is shown in Figures 8 and 9.

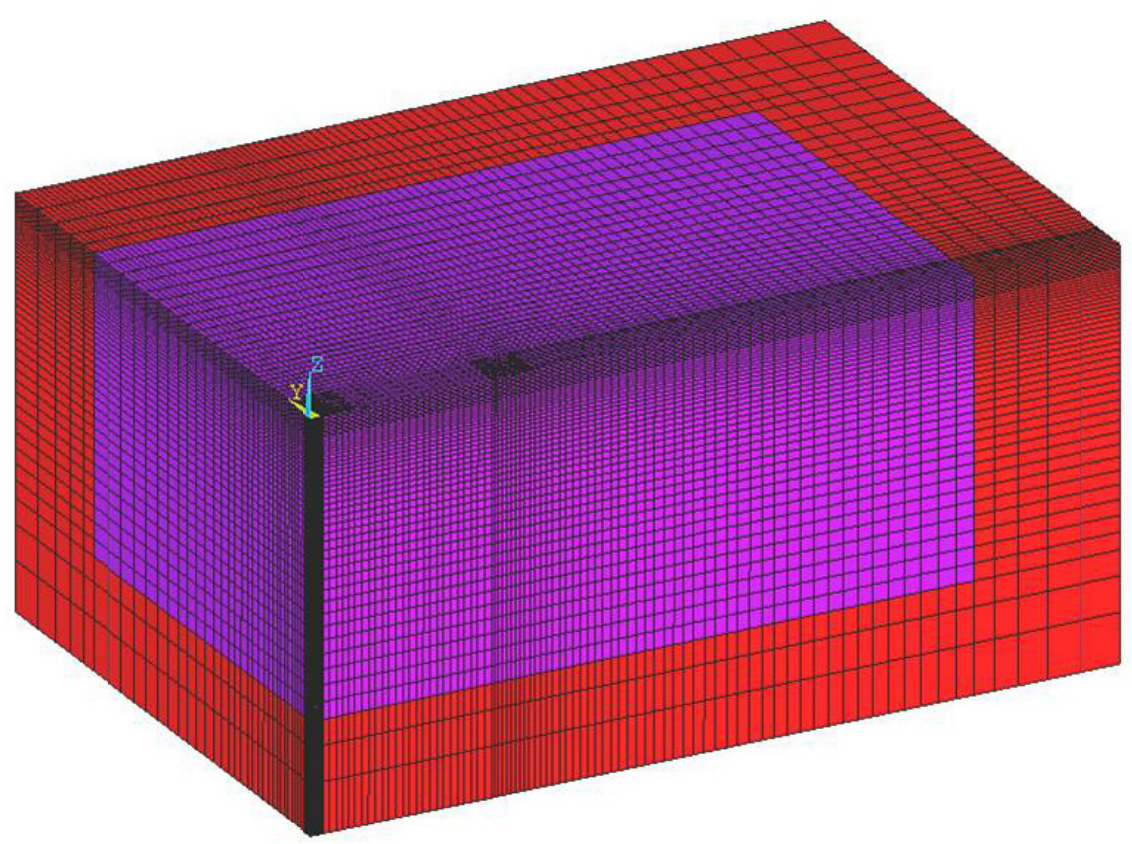

Figure 8. Meshing and boundary condition of model 


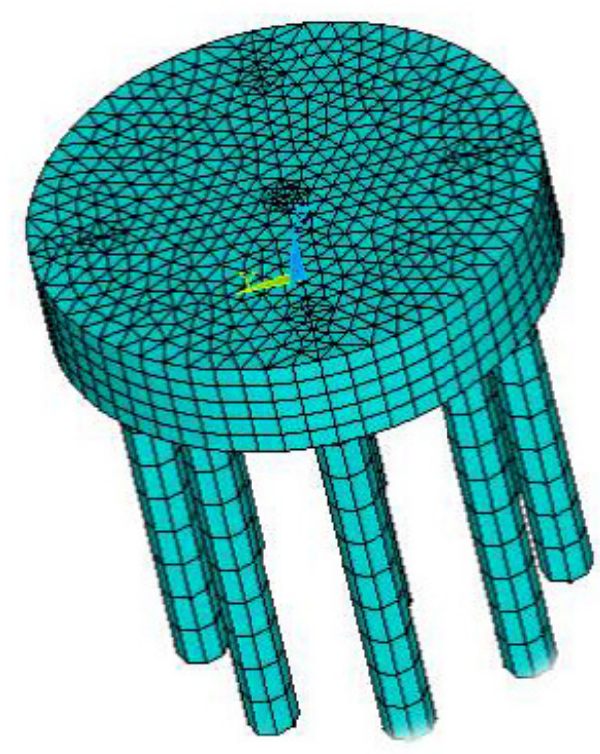

Figure 9. Meshing of the Deep Foundation

An amplitude reduction ratio, Arr, first proposed by Woods (1968-1969), to evaluate the trench effectiveness. Arr is the ratio of amplitude with trench and amplitude without trench.

$$
A r r=\frac{\text { Amplitude with trench barrier }}{\text { Amplited without trench barrier }}
$$

Aarr is the average of amplitude reduction ratio (Arr), and it is employed for investigating the screening effectiveness. Furthermore, Aarr is calculated along radial lines behind the trench and in the length of one Rayleigh wavelength.

$$
\operatorname{Aarr}=\frac{1}{n} l \int_{i=0}^{n l} \operatorname{Arr} d i
$$

$\mathrm{i}=$ is the distance between the trench and the outer edge of the foundation.

$\mathrm{n}=$ is the number of points along the distances

\section{Model Verification}

In order to investigate the validity of the obtained results from the current three-dimensional study, we compare the two-dimensional results of our study with the model of Beskoset al. (1986a) which was defined under the assumption of plain strain in two dimensional model by using BEM method and also, the researches of Ahmad and Al-Hussaini (1991) and EL Naggar and Chehab (2005) which have done by using ANSYS software (version 5.7). Finally, we developed this comparison for three-dimensional of current model. Figure 10exhibits an agreement between the current FEM model and the above researches.

The vertical and horizontal axis illustrates the Arr (Woods, 1968-1969) and trench location normalized by Rayleigh wavelength respectively. 


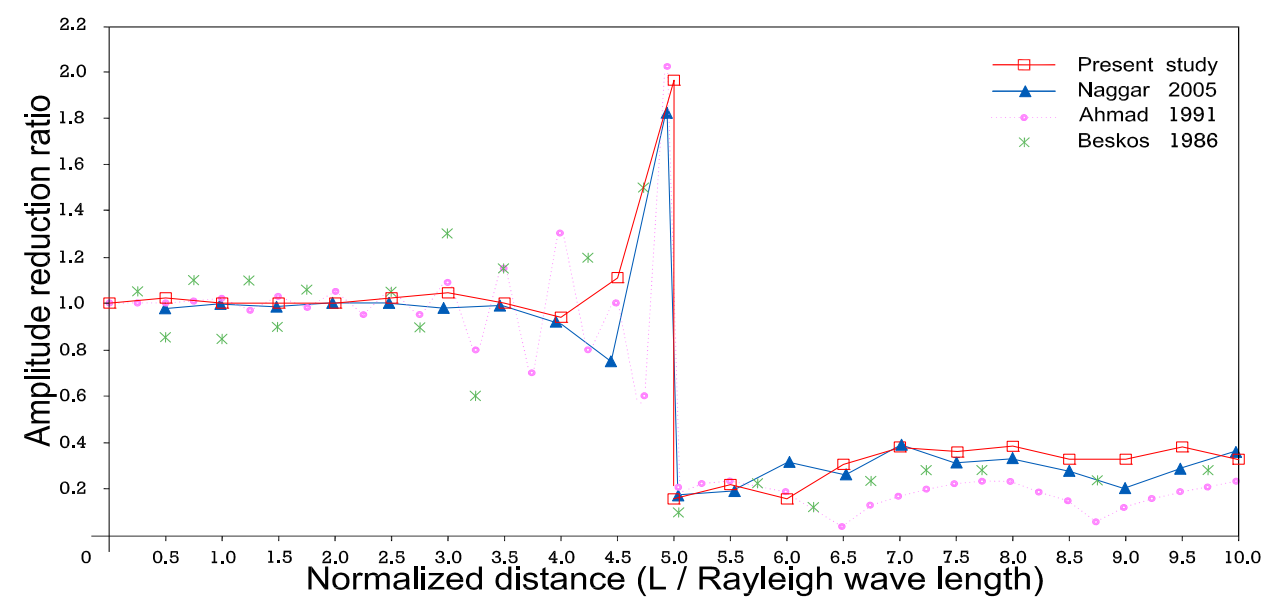

Figure 10. Comparative diagram

\section{Results and Discussion}

\subsection{The Evaluation of Amplitude Increasing before Trench}

As it can be seen in Figures 11 through 13, near the trench there is a dramatic increase in Arr. This result is caused by the following reasons:

1) When waves approach to an open trench which has an impedance coefficient equal to zero, they will be reflected with the same amplitude. This will emphasize the wave concentration near trench.

2) Excavating and removing the material from an open trench in actual situation causes a free movement for unrestrained trench edges because of its low stiffness. In conclusion, the wave amplitude near the trench edges increases in comparison with a model without open trench (Arr>1) (Jesmani et al., 2011).

In addition, as it can be seen in the Figures11 through 13, by increasing the trench angle, Arr increases. This issue is the result of increasing free nodes because of increase in trench dimension which increments the quantity of reflected waves.

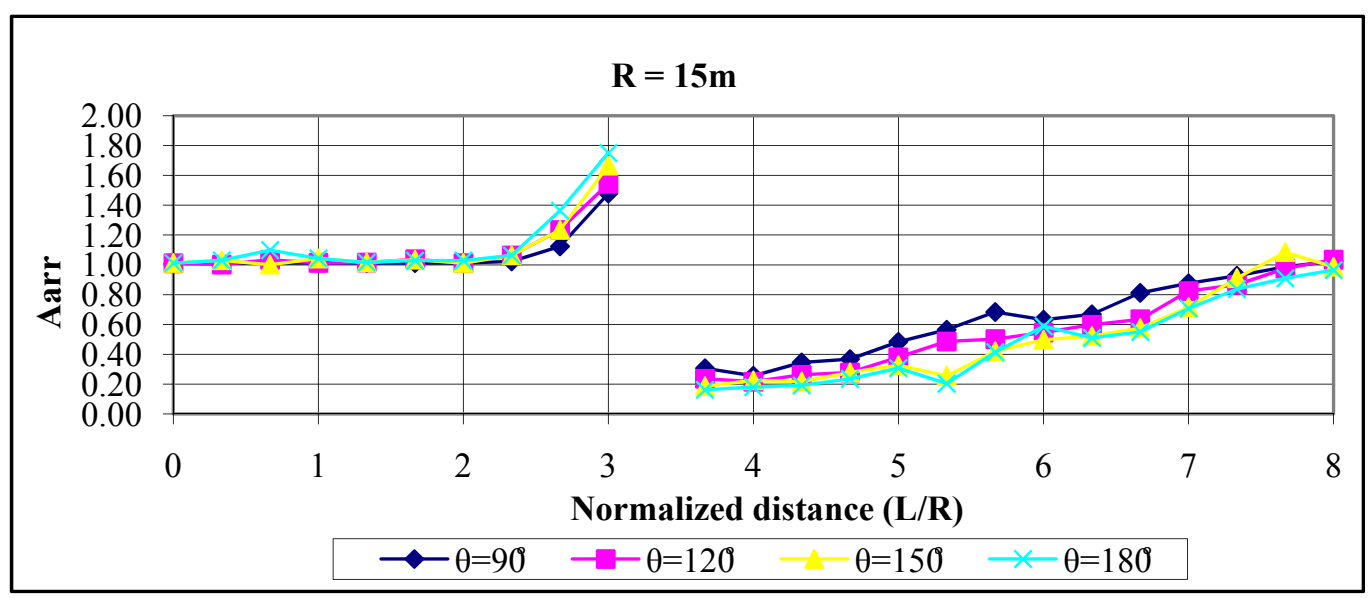

Figure 11. Amplitude Increasing before Trench $(\mathrm{D}=10 \mathrm{~m}, \mathrm{H}=20 \mathrm{~m}, \mathrm{R}=15 \mathrm{~m}$, Loading frequency=2Hz) 


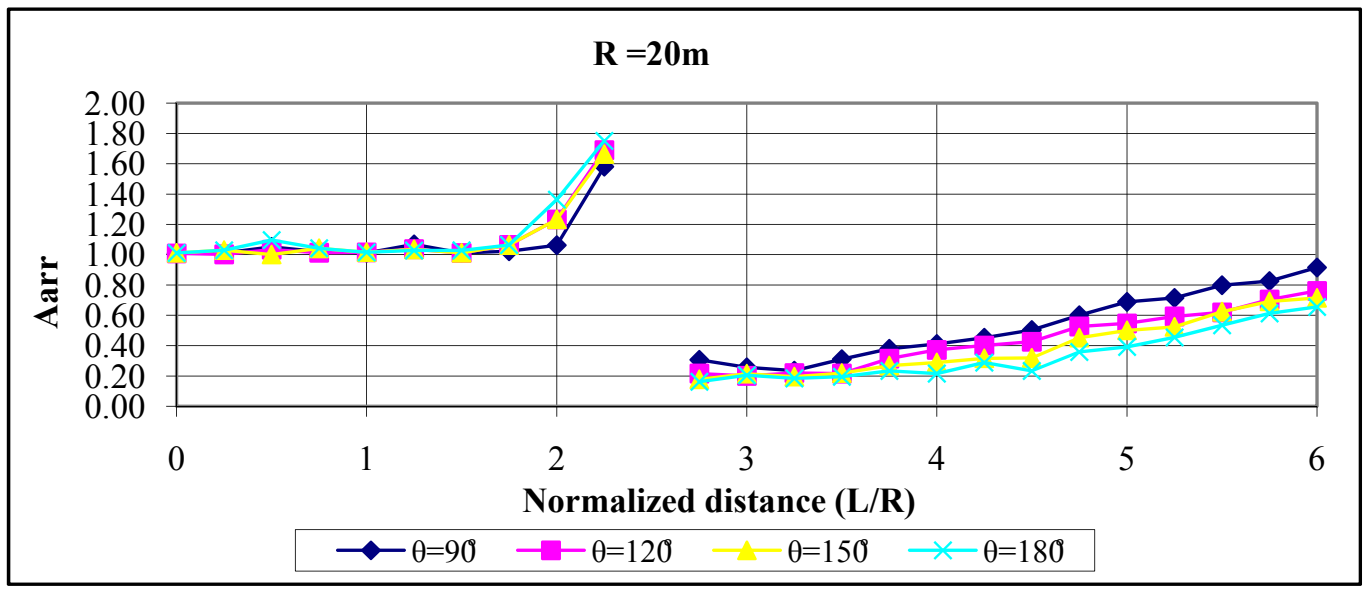

Figure 12. Amplitude Increasing before Trench $(\mathrm{D}=10 \mathrm{~m}, \mathrm{H}=20 \mathrm{~m}, \mathrm{R}=20 \mathrm{~m}$, Loading frequency=2Hz)

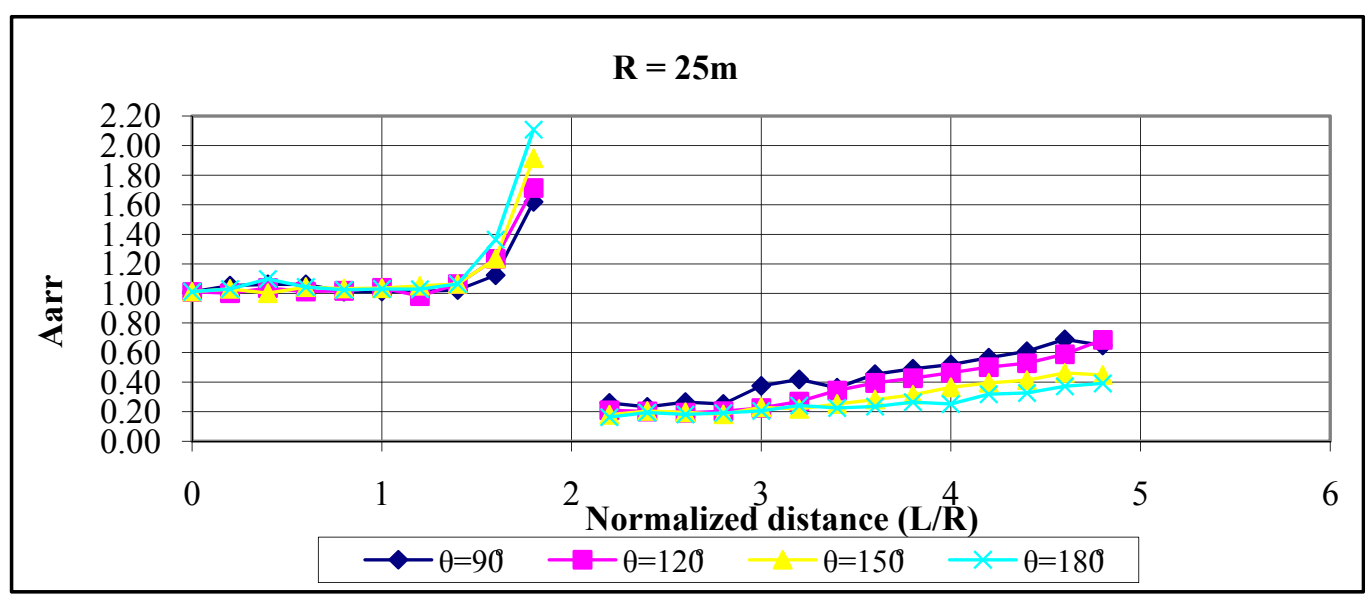

Figure 13. Amplitude Increasing before Trench $(\mathrm{D}=10 \mathrm{~m}, \mathrm{H}=20 \mathrm{~m}, \mathrm{R}=25 \mathrm{~m}$, Loading frequency=2Hz)

\subsection{The Effect of Open Trench Angle}

The effect of trench angle on Aarr is demonstrated in Figures 14 through 16 for $\mathrm{L}=\mathrm{R}, 2 \mathrm{R}$ and $3 \mathrm{R}$ middle distances. Generally, increasing the trench angle leads a decrease in Aarr. It also observed that the reduction rate in every curve decreases from the trench angle bigger than $\theta=150^{\circ}$. Thus $\theta=150^{\circ}$ is highly recommended for the optimal open trench angles. Theequations that have been presented near curves (because of the low coefficient of $x^{2}$ ) approximately show a linear behavior between Aarr and trench angle. In addition, it is noticeable that increasing the trench angle has the most effect on the rate reduction of studied points in the distance of $2 \mathrm{R}$ from the vertex of the trench. However, this fact is in its lower value in the distance of $\mathrm{R}$. 


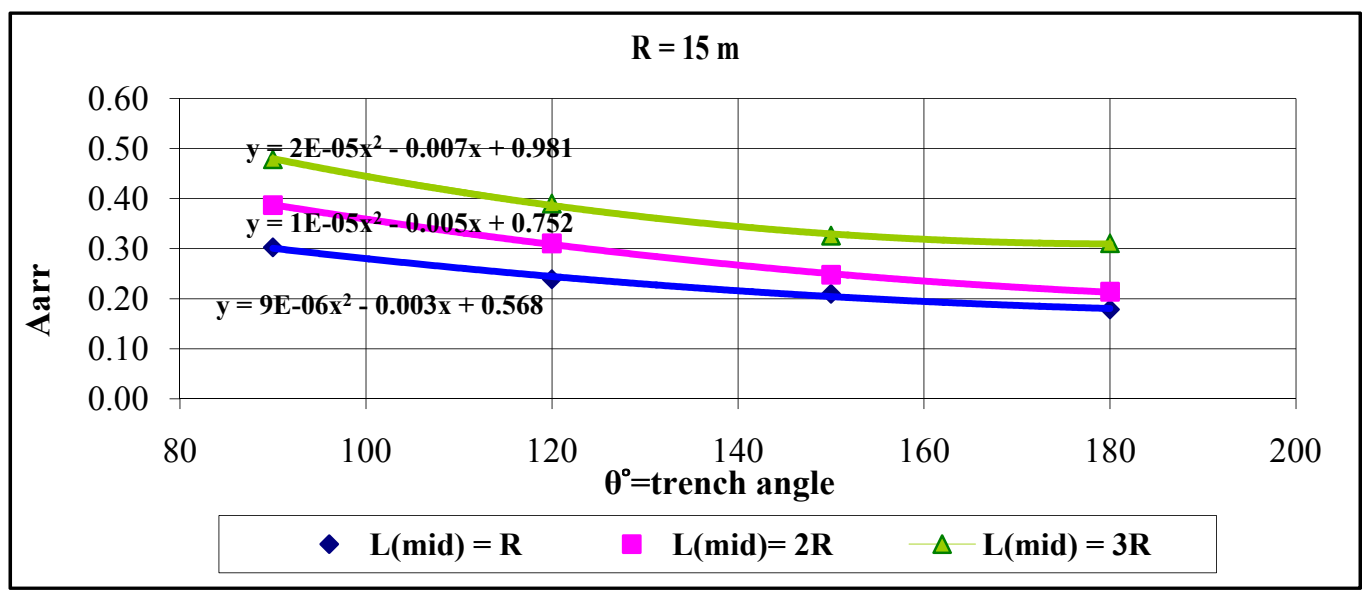

Figure 14. The Effect of Trench Angle $(\mathrm{D}=10 \mathrm{~m}, \mathrm{H}=20 \mathrm{~m}, \mathrm{R}=15 \mathrm{~m}$, Loading frequency $=2 \mathrm{~Hz})$

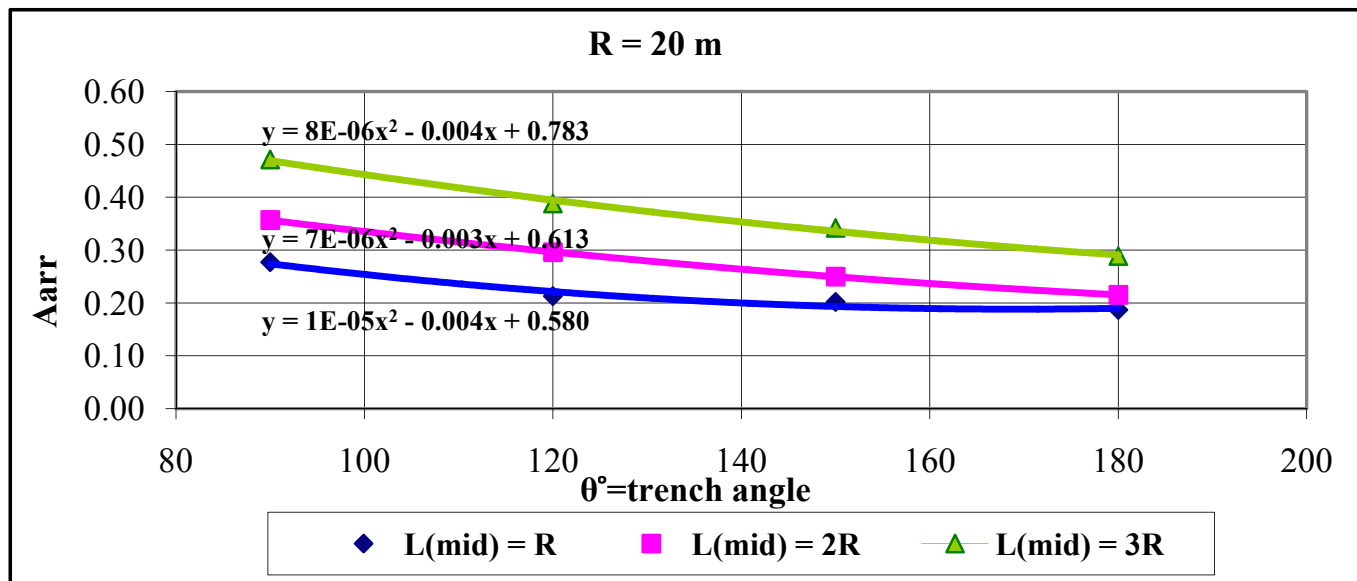

Figure 15. The Effect of Trench Angle $(\mathrm{D}=10 \mathrm{~m}, \mathrm{H}=20 \mathrm{~m}, \mathrm{R}=20 \mathrm{~m}$, Loading frequency $=2 \mathrm{~Hz})$

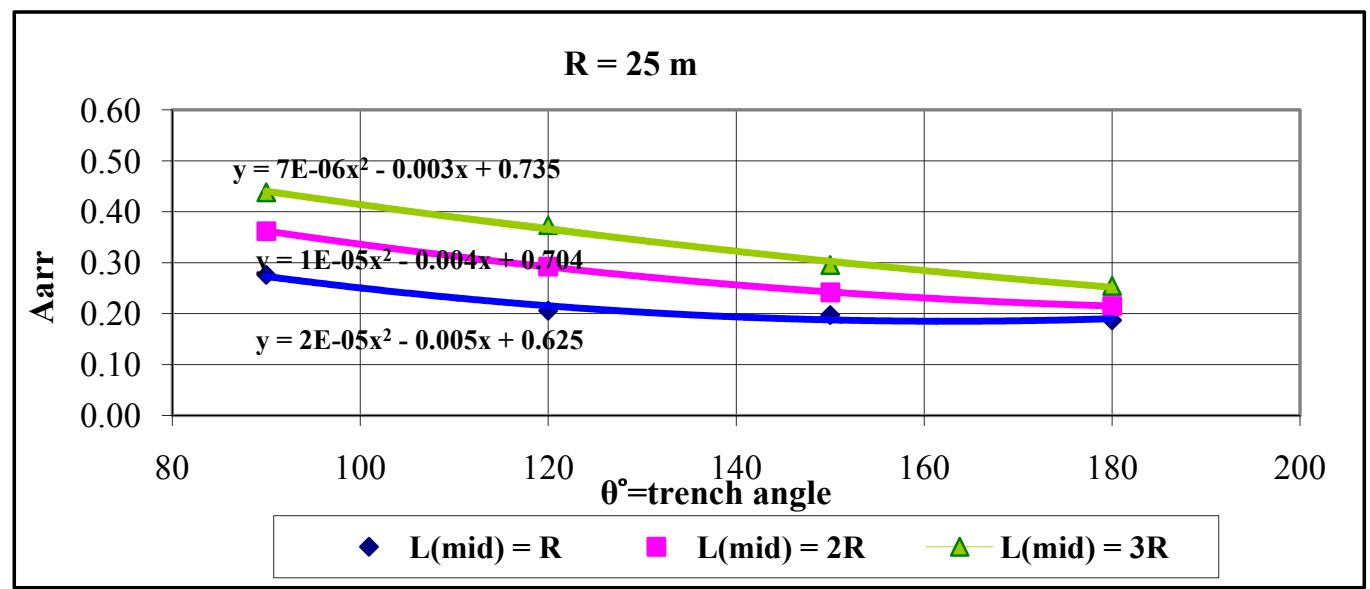

Figure 16. The Effect of Trench Angle $(\mathrm{D}=10 \mathrm{~m}, \mathrm{H}=20 \mathrm{~m}, \mathrm{R}=25 \mathrm{~m}$, Loading frequency $=2 \mathrm{~Hz}$

\subsection{The Effect of Open Trench Radius}

The effect of trench radius on Aarr is illustrated in Figures 17 through 20 for $\mathrm{L}=\mathrm{R}, 2 \mathrm{R}$ and 3R middle distances. As it can be seen in these figures, in a constant trench angle, increasing trench radius doesn't have an important effect on Aarr. Actually, in accordance with normalized distances by trench radius, the effect of trench radius 
increasing has been omitted. It can also be inferred that by increasing the trench radius, longer length of wave path will be protected.

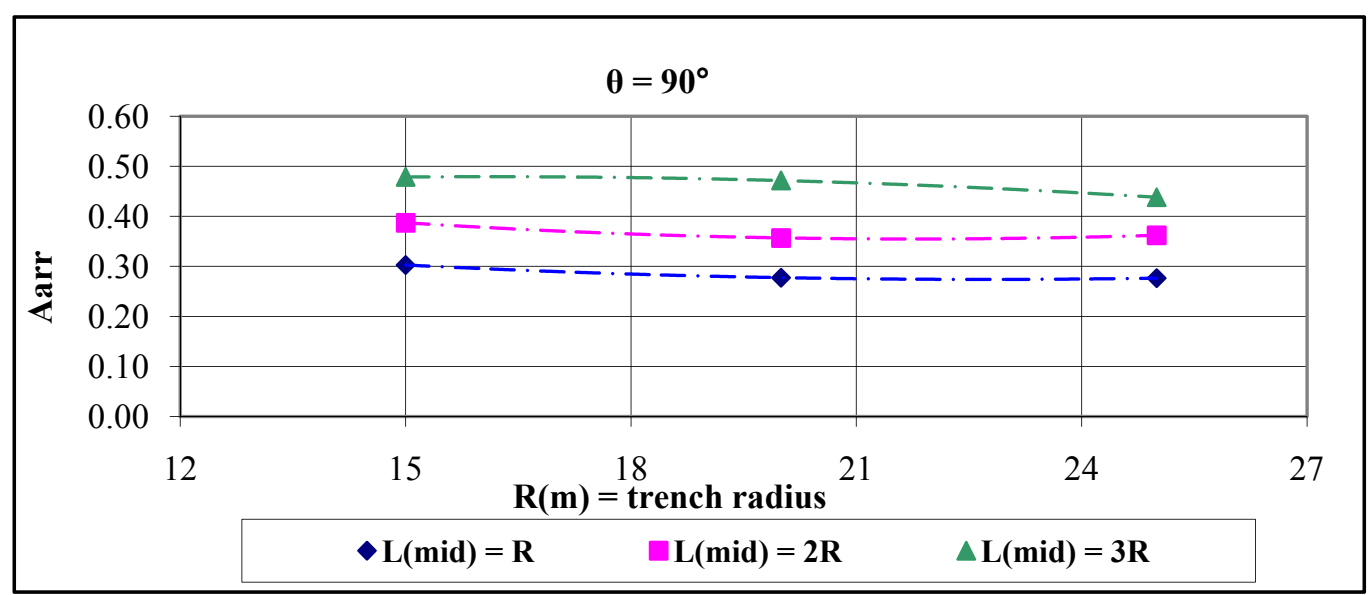

Figure 17. The Effect of Trench Radius $\left(\mathrm{D}=10 \mathrm{~m}, \mathrm{H}=20 \mathrm{~m}, \theta=90^{\circ}\right.$, Loading frequency $\left.=2 \mathrm{~Hz}\right)$

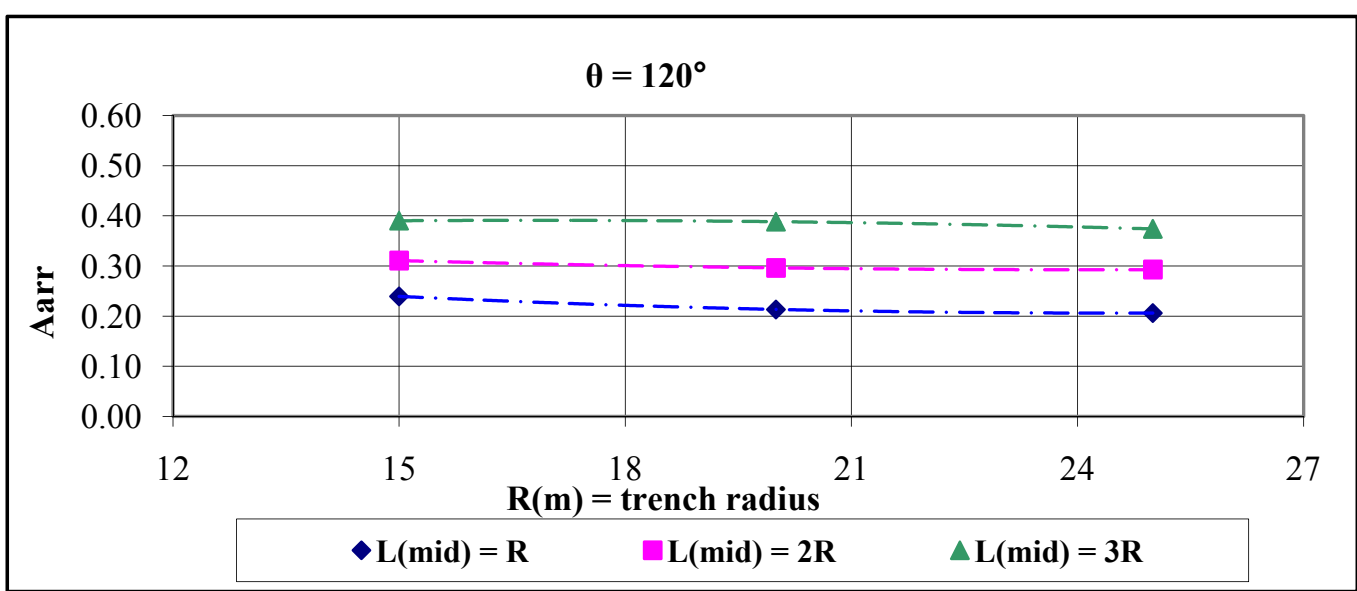

Figure 18. The Effect of Trench Radius $\left(\mathrm{D}=10 \mathrm{~m}, \mathrm{H}=20 \mathrm{~m}, \theta=120^{\circ}\right.$, Loading frequency=2Hz)

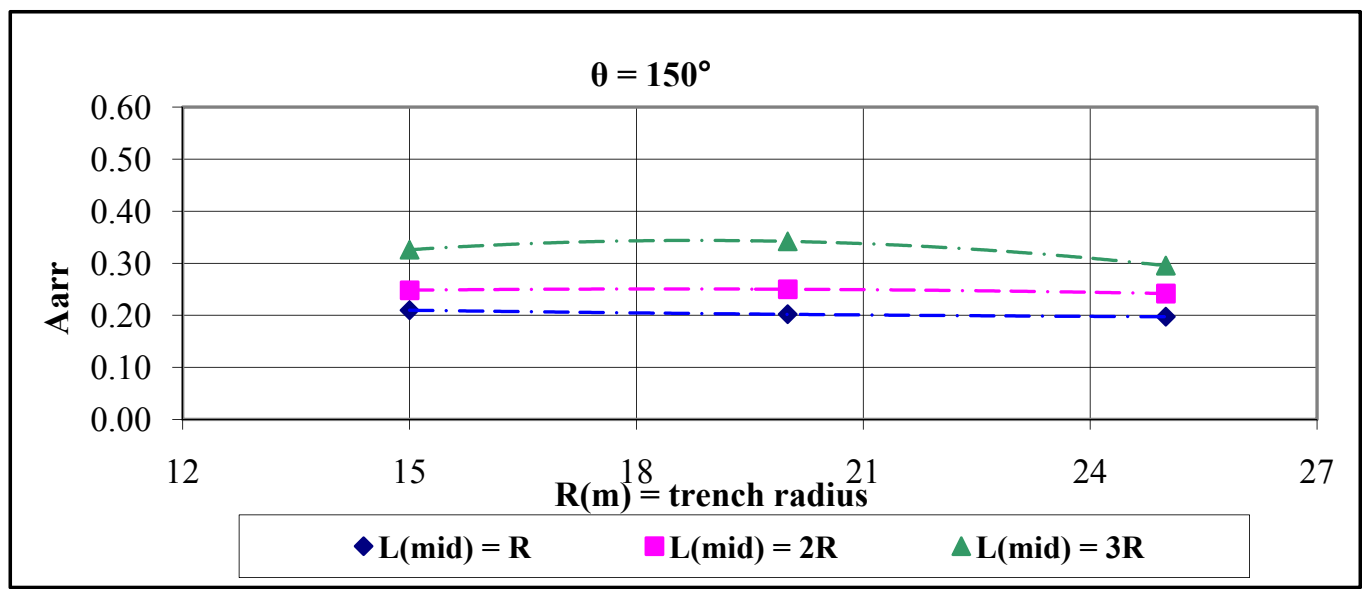

Figure 19. The Effect of Trench Radius $\left(\mathrm{D}=10 \mathrm{~m}, \mathrm{H}=20 \mathrm{~m}, \theta=150^{\circ}\right.$, Loading frequency $=2 \mathrm{~Hz}$ ) 


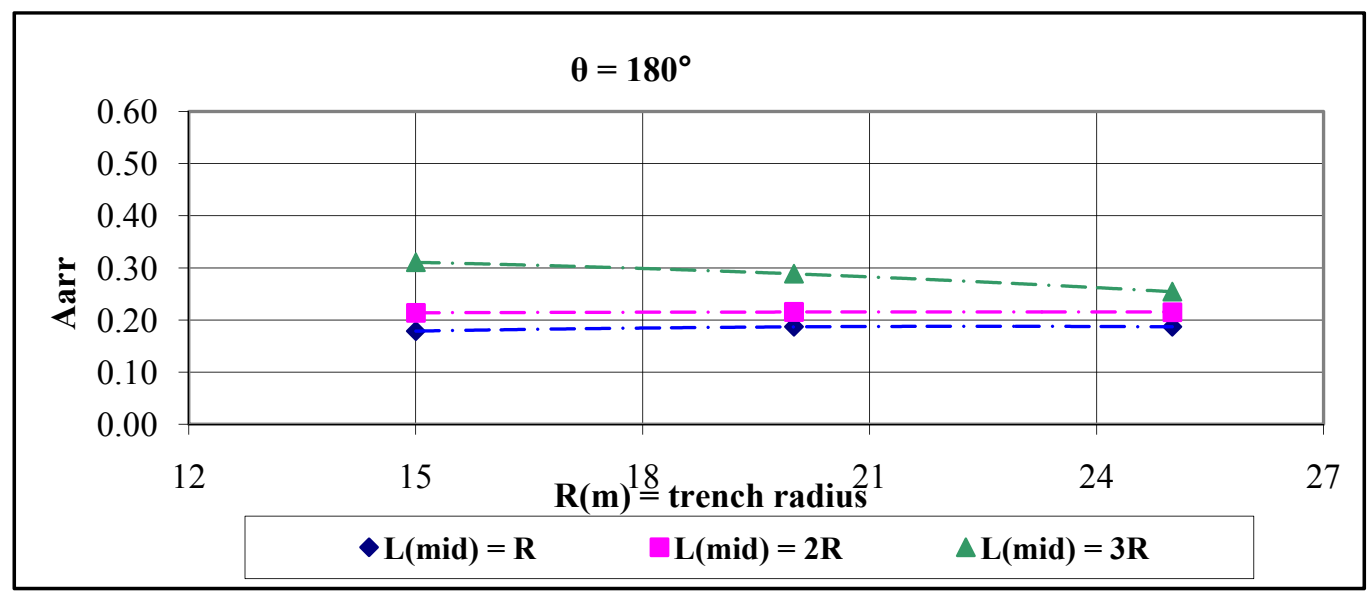

Figure 20. The Effect of Trench Radius $\left(\mathrm{D}=10 \mathrm{~m}, \mathrm{H}=20 \mathrm{~m}, \theta=180^{\circ}\right.$, Loading frequency $\left.=2 \mathrm{~Hz}\right)$

\section{Conclusions}

A three-dimensional finite element analysis of a vibration of deep foundation has been taken in this research to evaluate the effects of passive isolation on the reduction of wave amplitude and the following conclusions can be extracted.

- Increasing the trench radius has a direct effect on the protected area. Hence, by increasing the trench radius a bigger area will be protected.

- By keeping the trench angle unchangeable, increasing in trench radius doesn't have a significant effect on wave amplitude reduction. Therefore, it is better to investigate the interaction of trench radius and angle simultaneously and put the responsibility of wave reduction to the height and geometric properties of trench related to the trench length.

- Generally, increase in trench angle cause a decrease in average amplitude reduction ratio (Aarr).

- Trench angle $=150^{\circ}$ is highly recommended for the optimal open trench angles.

- The behavior of wave amplitude reduction versus the increase of trench angle is approximately linear.

\section{References}

Aboudi, J. (1973). Elastic Waves in Half-Space with thin Barrier. Journal of EngMech, ASCE, 99(1), 69-83.

Adam, M., \& Estorff, O. (2005). Reduction of Train-Induced Building Vibrations by Using Open and Filled Trenches. Computers and Structures, 83, 11-24. http://dx.doi.org/10.1016/j.compstruc.2004.08.010

Ahmad, S., \& Al-Hussaini, T. M. (1991). Simplified Design for Vibration Screening by Open and In-Filled Trenches. Journal of Geotechnical Engineering, ASCE, 117(1), 67-88.

Ahmad, S., \& Al-Hussaini, T. M. (1996b). Active Isolation of Machine Foundations by In-Filled Trench Barriers. $\begin{array}{lllll}\text { Journal of Geotechnical } & \text { Engineering, }\end{array}$ http://dx.doi.org/10.1061/(ASCE)0733-9410(1996)122:4(288)

Ahmad, S., \& Al-Hussaini, T. M. (2000). Numerical and Experimental Studies on Vibration Screening by Open and In-Filled Trench Barriers. International Workshop on Wave Propagation Moving Load and Vibration Reduction, Edited by Chouw, N., \& Schemid, G. WAVE2000, Rotterdam, Balkema, 241-250.

Ahmad, S., Al-Hussaini, T. M., \& Fishman, K. L. (1996a). Investigation on Active Isolation of Machine Foundations by Open Trenches. Journal of Geotechnical Engineering, ASCE, 122(6), 454-461. http://dx.doi.org/10.1061/(ASCE)0733-9410(1996)122:6(454)

Attewell, P. B., \& Farmer, I. W. (1973). Attenuation of Ground Vibrations from Pile Driving. Ground Engineering, 6(4), 26-29.

Barkan, D. D. (1962). Dynamics of Bases and Foundations. New York, NY: McGraw-Hill.

Beskos, D. E., Dasgupta, G., \& Vardoulakis, I. G. (1986a). Vibration Isolation Using Open or Filled Trenches. Part 1: 2D Homogeneous Soil. Computational Mechanics, 1(1), 43-63. http://dx.doi.org/10.1007/BF00298637

Beskos, D. E., Dasgupta, G., \& Vardoulakis. I. G. (1985). Vibration Isolation of Machine Foundations. Vibration 
Problems in Geotechnical Engineering, Edited by Gazetas, G., \& Selig, E. T. ASCE, NY. 138-151.

Beskos, D. E., Leung, K. L., \& Vardoulakis, I. G. (1986b). Vibration Isolation of Structures from Surface Waves in Layered Soil. Recent Application in Computational Mechanics, ASCE, NY. 125-140.

Beskos, D. E., Leung, K. L., \& Vardoulakis, I. G. (1990). Vibration Isolation Using Open or Filled Trenches. Part 3: 2D Non-Homogeneous Soil. Computational Mechanics, 7(1), 137-148.

Beskos, D. E., Leung, K. L., \& Vardoulakis, I. G. (1991). Vibration Isolation by Trenches in Continuously Non-Homogeneous Soil. By the BEM. Soil Dynamics and Earthquake Engineering, 10(3), 172-179. http://dx.doi.org/10.1016/0267-7261(91)90030-4

Celebi, E. (2006). Three-Dimensional Modeling of Train-Track and Sub-Soil Analysis for Surface Vibrations due to Moving Loads. Applied Mathematics and Computation, 1-22.

Celebi, E., Firat, S., \& Cankayac I. (2006). The Effectiveness of Wave Barriers on the Dynamic Stiffness Coefficient of Foundations Using Boundary Element Method. Applied Mathematics and Computation, 180(2), 683-699. http://dx.doi.org/10.1016/j.amc.2006.01.008

EL Naggar, M. H., \& Chehab, A. G. (2005). Vibration Barriers for Sock-Producing Equipment. Canadian Geotechnical Journal, 42, 297-306. http://dx.doi.org/10.1139/t04-067

Fuykui, M., \& Matsumoto, Y. (1980). Finite Difference Analysis of Rayleigh Wave Scattering at a Trench. BullSeismolSocAmer, ASCE, 2051-2069.

G. Segol, P. C. Y. Lee, \& J. F. Abel. (1978). Amplitude Reduction of Surface Waves by Trenches. Journal of Soil Mechanics and Foundations Division, ASCE, 104, 621441.

Gao, G. Y., Li, Z. Y., Qui, C. H., \& Yue, Z. Q. (2006). Three-Dimensional Analysis of Piles as Passive Barriers for Ground Vibration Isolation. Soil Dynamics and Earthquake Engineering, 26, 1015-1027. http://dx.doi.org/10.1016/j.soildyn.2006.02.005

Haupt, W. A. (1977a). Isolation of Vibrations by Concrete Core Walls. Proceeding 9th International Conference on Soil Mechanics an Foundation Engineering, Tokyo, Japan, 2, paper no. 251.

Haupt, W. A. (1977b). Surface Waves in non-homogeneous half space Proc. DMSR77 Karlsruhe 1, 355-367.

Karlstorm, A., \& A. Bostrom. (2007). Efficiency of Trenches Along Railways for Trains Moving at Sub or Supersonic Speeds. Soil Dynamics and Earthquake Engineering, 27, 625-64. http://dx.doi.org/10.1016/j.soildyn.2006.12.005

Kattis, S. E., Polyzos, D., \& Beskos, D. E. (1999). Vibration Isolation by a Row of Piles Using a 3D Frequency Domain BEM. International Journal for Numerical Methods in Engineering, 46, 713-728. http://dx.doi.org/10.1002/(SICI)1097-0207(19991020)46:5<713::AID-NME693>3.0.CO;2-U

Liao, S., \& Sangrey, D. A. (1978). Use of Piles as Isolation Barriers. Proc., ASCE, 104, 1139-1152.

M. Jesmani, A. Hamissi, M. Kamazare, \& R. Sadehi Vileh. (2011). Optimum Geometrical Properties of Active Isolation. Proceeding of the institution of civil engineering, Vol. 164.

M. Jesmani, A. Moghadam Fallahi, \& H. Faghihi Kashani. (2011). Study of Passive Isolation of Deep Foundation in Sandy Soil by Rectangular Trenches. EJGE Journal, 16, Bundle Q, 1297-1317.

M. Jesmani, M. R. Shafie \& R. Sadeghi Vileh. (2008). Finite Element Analysis of Active Isolation of Deep Foundation in Clayey Soil by Rectangular Trenches. EJGEJournal , 13, Bundle E, 1-16.

May, T. W., \& Bolt, B. A. (1982). The Effectiveness of Trenches in Reducing Seismic Motion. Journal of Earthquake Engineering and Structural Dynamics, 10(2), 195-210. http://dx.doi.org/10.1002/eqe.4290100203

Shen-Haw Jo, \& Hung-Ta, Lin. (2004). Analysis of Train-Induced and Vibrations and Vibration Reduction Schemes Above and Below Critical Rayleigh Speeds by Finite Element Method. Soil Dynamics and Earthquake Engineering, 24, 993-1002. http://dx.doi.org/10.1016/j.soildyn.2004.05.004

Shirvasta, R. K., \& Kameswara Rao, N. S. V. (2002). Response of Soil Media due to Impulse Loads and Isolation Using Trenches. Soil Dynamics and Earthquake Engineering, 22, 695-702. http://dx.doi.org/10.1016/S0267-7261(02)00060-X

Tsai, P. H. et al. (2007). Three-Dimensional Analysis of Screening Effectiveness of Hollow Pile Barriers for Foundation-Induced Vertical Vibration. Computer and Geotechnics, 35(3), 489-499. 
http://dx.doi.org/10.1016/j.compgeo.2007.05.010

Wass, G. (1972). Linear Two-Dimensional Analysis of Soil Dynamics Problems in Semi-infinite Layered Media. Phd Dissertation. Uni. of California at Berkley.

Wolf, J. P. (1994).Foundation Vibration Analysis Using Simple Physical Models. Englewood Cliffs, NJ: Prentice-Hall.

Woods, R. D. (1967). Screening of Surface Waves by Trenches. Phd Dissertation. Uni. Of Michigan, Ann Arbor. Mich.

Woods, R. D. (1968). Screening of Surface Waves in Soils. Journal of Soil Mechanics and Foundations Division, ASCE, 94(4), 951-979.

Woods, R. D. (1970). Vibration of Soils and Foundation. New Jersey: Prentice-Hall.

Woods, R. D., Barnett, N. E., \& Sagesser, R. (1974). Holography, a New Tool for Soil Dynamics. Journal of Geotechnical Engineering, ASCE, 100(11), 1231-1247.

Yeh, C. S., Liao, W. I., Tsai, J. F. \& Teng, T. J. (1997). Train Induced Ground Motion and its Mitigation by Trench and WIB. Report of NCREE-97-009, NAT. Center of Research on Earthquake Engineering, Taipi, Taiwan, R.O.C. 